REVIEW ARTICLE

\title{
Oyster Mushroom: Biochemical and Medicinal Prospects
}

\author{
FR Mowsumi ${ }^{1}$ and MBK Choudhury ${ }^{2}$ \\ ${ }^{1}$ National Mushroom Development Project, Savar, Dhaka \\ ${ }^{2}$ Directorate General Health Services, Dhaka
}

ABSTRACT

Mushroom possesses a vital portion of fungal kingdom creating a huge diversity. As a food major portion of these are unfit but as a whole these play an important role to maintain a sound health. Among them some are used as food and some as medicine. Many unknown mysterious components, very much needed for homeostasis of human body, are present in mushroom, which are now recognized as important area for biomedical researches. Oyster mushroom (Pleurotus ostreatus) is such a mushroom which is used both as food and medicine to ensure the fitness of body. It contains protein, carbohydrates, fat, fiber, water, different kinds of vitamins and minerals as well as secondary metabolites. Its statins are outstanding in decreasing the harmful plasma lipids and in reducing blood pressure thereby reducing the risk of cardiovascular diseases. The beta-glucan component of oyster stimulates the immune system of the body. This mushroom is also found to be effective and beneficial in diabetes, cancer, microbial infections and so on. However, there are many other life saving components in oyster mushroom whose nature, effectiveness and mode of actions are yet to be characterized and defined. These valuable unknown informations are now subjects of researches. Bangladesh, like other countries of the world is conducting such type of researches but still has to go a long way in this field. At this very moment, it can be said beyond any doubt that oyster mushroom is very good as an alternative food and as a medicine.

Key Words: Oyester Mushroom, Beta-Glucan, Statin

Mushrooms are basically fungi, which have a fleshy and spore-bearing fruiting body. They have been in use not only for consumption purposes but also for medicinal purposes since ages. There are over 14,000 types of mushrooms in the world, out of which about 3,000 are edible, about 700 are found to have known medicinal properties and around 1400 are recognized to be poisonous ${ }^{1}$. Today mushrooms are eaten by people for their flavor, texture as well as for the health benefits they accord. Mushrooms do certainly have enormous potential for feeding third world peoples. In the west, mushrooms are regarded as a luxury food. But in many developing countries of the world, mushroom can mean cash for the poor and a new source of nutrition.

The oyster mushroom, first cultivated in Germany as a subsistence measure during World
War ${ }^{2}$ is now grown commercially around the world for food. There are many different varieties of the exotic oyster mushroom which are found throughout North America, Europe and Asia. The fluted, graceful oyster shell shape and delicate, briny flavor are best praised in a poem written during the Sung dynasty that calls the oyster "the mushroom of flower heaven".

In Japanese, Korean and Chinese cookery oyster mushroom is frequently used as a delicacy. It is frequently served on its own as soup, sometimes stuffed, or in stir-fry recipes with soya sauce. In Asian cooking practice oyster mushrooms are sometimes made into a sauce, which is similar to oyster sauce ${ }^{2}$.

Nutritional value of oyster mushroom is also appreciable. $3.5 \mathrm{oz}$. of oyster mushroom 
provides 38 Calories and contain, $15 \%-25 \%$ of Protein, $2.2 \mathrm{~g}$ of Fat, $6.5 \mathrm{~g}$ of Carbohydrate, $2.8 \mathrm{~g}$ of Fiber, and also containsVitamin $\mathrm{B}_{1}$ (Thiamine) $0.56 \mathrm{mg}$, Vitamin $\mathrm{B}_{2}$ (Riboflavin) $0.55 \mathrm{mg}$, Vitamin $\mathrm{B}_{3}$ (Niacin) $12.2 \mathrm{mg}$, Phosphorus $140 \mathrm{mg}$, Calcium $28 \mathrm{mg}$, Iron 1.7 $\mathrm{mg}^{3}$. Comparatively it is high in fiber and low in carbohydrate and fat which make it more potential for both normal people and patients.

Malnutrition in Bangladesh is among the highest in the world. More than 54\% of pre-school children are stunted, 56\% are under weight and more than $17 \%$ are wasted. Malnutrition among women is also extremely prevalent in Bangladesh. More than 50\% women suffer from chronic energy deficiency ${ }^{4}$. The rapid population growth resulting in high food requirements poses a difficult challenge given the limited availability of cultivable land in Bangladesh. There is a clear need to diversify food sources both in terms of land and environmental sustainability to develop the rural economy and to increase consumption of food to achieve improvements in the nutritional status of the people of Bangladesh. In the context of prevailing situations mushrooms, can play an important role in improving the nutritional status of the population.

Oyster mushroom can help in solving the problems of malnutrition and disease. Its protein content is second to legumes and quality is nearly equal to animal derived protein. Low fat content of oyster is mostly of the healthy unsaturated types. It contains the minerals mainly required by the human body, such as calcium, phosphorous and iron, in twice the amounts contained in beef, pork and chicken meat. It has the highest content of Vitamin $B_{1}$ and $\mathrm{B}_{2}$. It is rich in folic acid content which can prevent and cure anemia and 5 to 10 times richer in niacin than any other vegetable. Oyster mushroom is also suitable for people wishing to reduce their weight. It has been used to relax muscles, to resist leakage of blood vessels and in strengthening of veins and relaxation of the tendons ${ }^{1}$.
In developing countries like Bangladesh chronic life threatening health problems such as diabetes, cardiovascular disease and obesity are becoming very common in the affluent section of the population creating tremendous pressure on health care delivery system. Because of their high medicinal value, consumption of oyster mushrooms can aid in ameliorating \& preventing many ailments: liver ailments, high blood cholesterol level, kidney problems, diabetes, hypertension, heart disease, gastric cancers, impaired immune response, hepatitis $\mathrm{B}$, chronic fatigue syndrome, microbial infection $5,6,7$.

For the past 20 years, interest in the medicinal aspects of oyster mushrooms has greatly been stimulated by the large number of scientific studies conducted on mushrooms. Folklores have provided clues for potential sources of medicine from mushrooms. Using modern approaches, scientists have isolated and identified specific components that can help prevent or sometimes cure of mankind killer diseases: heart diseases, diabetes, and cancer. As a result, a vast body of scientific literature concerning mushrooms has been published, mostly in hospitals and research institutions in Europe, Japan, China and United States. Following these leading countries Bangladesh has already started its journey to the goal.

Beneficial effects of wood-rotting mushrooms (that include oyster mushroom) on human being have been known for a long time. They have positive effects on blood lipid profile when consumed in large quantities because of their high content of fiber and natural production of substances suppressing the production of cholesterol. Oyster mushroom also contains many vitamins $(\mathrm{B}, \mathrm{D}, \mathrm{C}, \mathrm{K})$, minerals, trace elements ( $\mathrm{Na}, \mathrm{Cr}, \mathrm{Cu}, \mathrm{I}, \mathrm{Se}, \mathrm{Zn})$ and some fatty acids. Beyound doubt, the oyster mushroom is found to have positive impact on the organism and is considered as component food of healthy diet. So far modulation of immune response is concerned, the effect of the oyster mushroom itself (most frequently as dry powder) is negligible. 
Oyster mushroom significantly reduces the hepatocellular enzyme Aspartate transaminase (AST) and Alanine transaminase (ALT) in plasma $^{8}$. Although the exact mechanism is not clear but it might be due to presence of various hepatoprotective substances present in Pleurotus ostreatus. In a study Bobek et al. (1997) observed a significant reduction of cholesterol in serum $(31-46 \%)$ and in liver $(25-30 \%)$ in Wister rats fed a diet containing $5 \%$ Pleurotus ostreatus for 52 weeks ${ }^{9}$. These observations were supported by the findings of Hossain et al. $(2003)^{10}$. They suggested that 5\% Pleurotus ostreatus supplementation provides health benefits, at least partially, by acting on the atherogenic lipid in hypercholesterolaemic condition. It is now established that excess lipid accumulation in the liver causes fatty change and ultimately responsible for hepatocellular injury. In a study Jayakumar et al. (2006) ${ }^{11}$ observed that administration of the extract of Pleurotus ostreatus reduces significantly the plasma level of AST, ALT and Alkaline phosphatase (ALP) and increases significantly the hepatic concentration of antioxidant enzymes reduced glutathione (GSH), catalase (CAT), superoxide dismutase (SOD) and glutathione peroxidase (Gpx) on Carbon tetra chloride (CCl4) induced liver damage in male Wister rats. Although lots of study conducted in different corners of the world with Pleurotus ostreatus but most of them were limited in animal subjects. A study was conducted by Choudhury et al. (2009) ${ }^{8}$ among the targeted human population which is consistent with Bobek et al. (1997) 9 and Jayakumar et al. (2006) 11 that gives the guidelines of hepatoprotective effects of oyster mushroom.

In vivo researches have shown that consumption of oyster mushrooms lowers cholesterol levels $9,10,12-22$, which is because these mushrooms naturally contain statins such as lovastatin $^{23}$. Studies have shown that the mushrooms contain up to $2.8 \%$ lovastatin on a dry weight basis 24 . Both lovastatin and its hydroxyacid metabolite are highly bound ( $>$ $95 \%$ ) to human plasma proteins. Animal studies demonstrated that lovastatin crosses the bloodbrain and placental barriers ${ }^{25}$. Statins (or HMGCoA reductase inhibitors) lower cholesterol levels by inhibiting the enzyme HMG-CoA reductase, which plays a central role in the production of cholesterol in the liver. Increased cholesterol levels have been associated with cardiovascular diseases (CVD), and statins are therefore used in the prevention of these diseases. Pleurotus ostreatus also contains the hypocholesterolaemic agent mevinolin (monacolin K, lovastatin) which may be involved in decreasing the activity of the 3hydroxy-3-methylglutaryl coenzyme A (HMGCoA) reductase enzyme. $P$. ostreatus contains water-soluble gel-forming substances, including $\beta-1,3-D-$ glucan and pectin, which bind to bile acids, thereby inhibiting cholesterol-bile micelle formation and cholesterol absorption ${ }^{10}$.

Pleurotus ostreatus feeding may cause the suppression of endogenous cholesterol biosynthesis by inhibiting the activity of HMGCoA reductase. Mushroom feeding also significantly decreased hepatic cholesterol suggesting the clearance of this sterol component from liver tissue. This may relate to the mushroom-induced enhanced activity of $7 \alpha-$ hydroxylase (a key enzyme of cholesterol catabolism) and bile acid secretion and the subsequent increased excretion of cholesterol through the faeces ${ }^{10}$. Hypercholesterolaemia produces oxidative stress ${ }^{26}$ and for such case anti-oxidants, particularly reduced glutathione, are important factors involved in bile formation and bile flow and act as a driving force ${ }^{27}$. In literature, the mechanism of oyster mushroom's hypocholesterolemic effects (lowering cholesterol) lies with its ability to reduce cholesterol absorption from GIT and endogenous synthesis and increase plasma cholesterol removal by reducing the production 


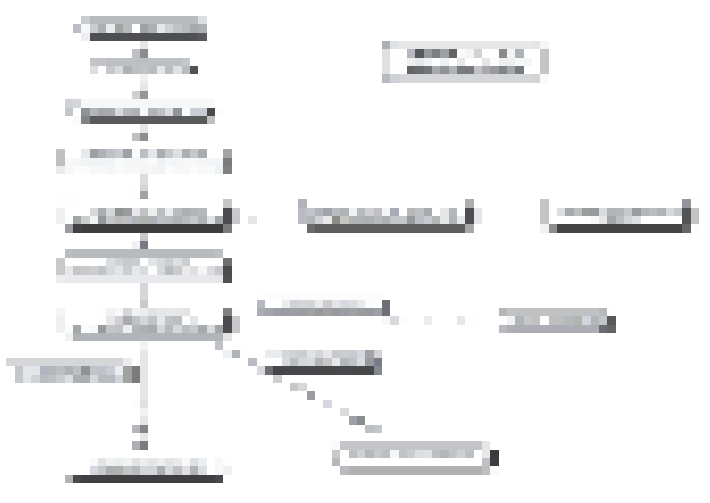

Fig 1: Cholesterol biosynthetic pathway

Fig 2: HMG CoA reductase reaction

and secretion of very low density lipoproteins (VLDL). Rats were fed on a semisynthetic diet containing $0.3 \%$ of cholesterol with added $5 \%$ of powdered oyster mushroom for 8 weeks. It was observed that after 8 weeks, the level of serum cholesterol dropped significantly by $36 \%$; and the accumulation of cholesterol and triglycerides in the liver fell by $51 \%$ and $32 \%$, respectively. Parallel reductions of cholesterol also occurred in very low density lipoproteins (VLDL) (by 53\%) and in low density lipoproteins (LDL) (by 47\%) 28 .

Several studies have found that a blood pressure reduction is associated with the use of statins. In a study Glorioso et al., (1999) randomized 30 persons with moderate hypercholesterolemia and untreated hypertension in a double-blind manner to placebo or pravastatin group in a crossover design after an 8-week placebo and diet run-in period. In 25 participants who completed the 32week trial, pravastatin decreased total and LDL cholesterol, systolic and diastolic blood pressure, and pulse pressure and blunted the blood pressure increase caused by the cold pressor test compared with placebo ${ }^{29}$.
Pleurotus ostreatus was found to possess hypoglycemic effects in experimentally induced diabetic rats $^{20}$ and in diabetic subjects ${ }^{12}$. $P$. ostreatus feeding to streptozotocin-induced diabetic rats significantly lowered both basal and post-prandial glycaemia ${ }^{20}$. Accordingly, it could be assumed that $P$. ostreatus feeding helps in reducing the atherogenic lipid seen in association with diabetes-related complications. In another study Choudhury et al., (2008) randomly selected total 36 subjects who were supplemented with $15 \mathrm{~g}$ mushroom powder splitted into 3 equal doses per day and effect was observed on blood glucose and blood pressure after 1 month. Study showed that oyster mushroom significantly reduces blood glucose level of hyperglycemic subjects and also reduces blood pressure level (both systolic and diastolic) of hypertensive subjects. But there were no significant effect on normoglycemic and normotensive subjects. The result of this study also conveyed the message that oyster mushroom may reduce body weight of an obese person, relieve constipation and hence can prevent related diseases ${ }^{30}$.

Oyster mushroom is very much rich in fiber. These fibers bind the cholesterols in gut, fecilititate its fecal excretion from the body. Moreover, fibers forms and increase the bulk of stool, speed bowel movement, decrease the discharge time and thus reduce the risk of colon cancer and other gastrointestinal tract related disturbances. But oyster mushrooms contain small amounts of arabitol, a sugar alcohol, which may cause gastrointestinal upset in some people.

Research with Pleurotus ostreatus demonstrated activity against various cancer cell lines ${ }^{31}$ and animals studies have shown an anticancer effect $^{32,33}$. $\beta$-glucan (pleuran), a group of immunomodulating substances called PAMP (pathogen associated molecular patterns) is contained in the cell walls of oyster mushrooms. These molecules are non-specifically identified by the components of the immune system as the 
structures against which the immune response must be activated. The effect of $\beta$-glucan is realized through a direct contact with immunocompetent cells, macrophages ${ }^{34}$. So oyster mushroom is beneficial to boost the immune system of body.

$\beta$-glucan molecules of oyster enhance the immune system of body to help fight abnormal cells as well as boost the system against damaging effects of chemo and radiation therapies used to kill tumor cells. Tablets and elixirs, formulated from purified glucan extracted from Pleurotus ostreatus, are now available for strengthening the immune system and lowering the serum cholesterol levels to prevent heart diseases. According to much folklore, Pleurotus can also prevent high blood pressure, impart long life and vigor and assist people in recovering from fatigue. It can also prevent hangovers, constipation, obesity and is an aphrodisiac $^{35}$.

In conclusion, Pleurotus ostreatus ingestion has significant health benefits through the modulation of physiological functions that include various atherogenic lipid and antioxidants in hypercholesterolemia, glucose in diabetes, bile acid secretion etc. Although mushrooms are increasingly being recognized as important food products for their significant role in human health, nutrition and disease, their consumption in many developing countries, particularly in Bangladesh, is extremely limited, one reason probably being that the health benefits derived from various edible mushrooms are largely unknown to our people. Thus, one of the objectives of the present document is to generate awareness of the beneficial effects of oyster mushroom.

\section{References}

1. Annonymous. http://lifestyle.iloveindia. com/lounge/ benefits-of-mushrooms-1337.html.

2. Eger G, Eden G \& Wissig E. Pleurotus ostreatus breeding potential of a new cultivated mushroom. Theoretical and Applied Genetics 1976; 47: 155-163.

3. Annonymous http:// countylinemushrooms. com/oyster nutritional value. html.

4. Annonymous. Nutrition Country Profiles: Bangladesh summary. Food and Agriculture Organization (FAO) Country profiles 2008; L-2.

5. Wasser, SP \& Weis AL. Therapeutic properties of substances occurring in higher Basidiomycetes mushrooms: a modern perspective. Crit Rev Immunol 1999; 19: 65-95.

6. Gunde-Cinoerman N. Medicinal value of the genus Pleurotus (Fr) P. Karst. Int J Med Mushroom 1999; 1: 69-70.

7. Ooi VEC. Medicinally important fungi. In: Science and Cultivation of Edible Fungi. (Ed) V. Griensven. Balkema, Rotterdam 2000: 41-51.

8. Choudhury MBK, Mowsumi FR, Mujib TB, Sarker NC, Choudhuri MSK \& Shahdat M. Effect of Oyster Mushroom (Pleurotus ostreatus) on hepatocellular markers alanin aminotransferase and aspartate aminotransferase of adult human during Ramadan. Bangladesh J Mushroom 2009; 3(2): 7 11.

9. Bobek P, Ozdín L, Kuniak L and Hromadová M. Regulation of cholesterol metabolism with dietary addition of oyster mushrooms (Pleurotus ostreatus) in rats with hypercholesterolemia. Cas Lek Cesk 1997; 136: 186-190.

10. Hossain S, Hashimoto M, Choudhury EK, Alam N, Hussain S, Hasan M et al. Dietary mushroom (Pleurotus ostreatus) ameliorates atherogenic lipid in hypercholesterolaemic rats. Clin Exptl Pharmacol Physiol 2003; 30: 470-475.

11. Jayakumar $\mathrm{T}$, Ramesh $\mathrm{E}$ and Geraldine $\mathrm{P}$. Antioxidant activity of the oyster mushroom, Pleurotus ostreatus, on $\mathrm{CCl} 4$ induced liver injury in rats. Food Chem Toxicol 2006; 44:1989-1996.

12. Khatun K, Mahtab H, Khanam PA, Sayeed MA and Khan KA. Oyster mushroom reduced blood glucose and cholesterol in diabetic subjects. Mymensingh Med J 2007; 16: 94-99.

13. Bobek P and Galbavý S. Hypocholesterolemic and antiatherogenic effect of oyster mushroom (Pleurotus ostreatus) in rabbits. Nahrung 1999; 43(5): 339-342.

14. Bobek P, Ozdín L and Galbavý S. Dose- and timedependent hypocholesterolemic effect of oyster mushroom (Pleurotus ostreatus) in rats. Nutrition 1998; 14(3): 282-286.

15. Bajaj M, Vadhera S, Brar AP and Soni GL. Role of 
oyster mushroom (Pleurotus florida) as hypocholesterolemic/antiatherogenic agent. Indian J Exp Biol 1997; 35: 1070-1075.

16. Bobek P, Ozdín L and Kuniak L. Effect of oyster mushroom (Pleurotus Ostreatus) and its ethanolic extract in diet on absorption and turnover of cholesterol in hypercholesterolemic rat. Nahrung 1996; 40: 222-224.

17. Bobek P, Ozdín O and Mikus M. Dietary oyster mushroom (Pleurotus ostreatus) accelerates plasma cholesterol turnover in hypercholesterolaemic rat. Physiol Res 1995; 44: 287-291.

18. Bobek P, Ozdin L and Kuniak L. The effect of oyster mushroom (Pleurotus ostreatus), its ethanolic extract and extraction residues on cholesterol levels in serum, lipoproteins and liver of rat. Nahrung 1995; 39: 98-99.

19. Bobek P, Ozdin L and Kuniak L. Mechanism of hypocholesterolemic effect of oyster mushroom (Pleurotus ostreatus) in rats: reduction of cholesterol absorption and increase of plasma cholesterol removal. Z Ernahrungswiss 1994; 33 : 44-50.

20. Chorváthová V, Bobek P, Ginter E and Klvanová J. Effect of the oyster fungus on glycaemia and cholesterolaemia in rats with insulin-dependent diabetes. Physiol Res 1993; 42(3): 175-179.

21. Bobek P, Ginter E, Jurcovicová M and Kuniak L. Cholesterol-lowering effect of the mushroom Pleurotus ostreatus in hereditary hypercholesterolemic rats. Ann Nutr Metab 1991; 35: 191-195.

22. Ginterová A and Janotková O. Utilization of fat and degradation of cholesterol by Pleurotus spp. Folia Microbiol. (Praha) 1981; 26: 228-231.

23. Gunde-Cimerman $\mathrm{N}$ and Cimerman A. Pleurotus fruiting bodies contain the inhibitor of 3-hydroxy-3methylglutaryl-coenzyme A reductase-lovastatin. Exp Mycol 1995; 19: 1-6.

24. Annonymous. http:/www znaturforsch. com/ac/ v58c/s58c0062.pdf

25. Annonymous. Lovastatin. Rxlist.com. http://www.rxlist.com/cgi/generic/lovastat.htm

26. Joseph JA, Vollalobos-Molina R, Denisova N, Erat $\mathrm{S}$, Cutler $\mathrm{R}$ and Strain J. Age differences in sensitivity to $\mathrm{H} 2 \mathrm{O} 2$ - or $\mathrm{NO}$-induced reductions in $\mathrm{K}+$-evoked dopamine release from superfused striatal slices: Reversals by PBN or Trolox. Free Radic Biol Med 1996; 20: 821-830.
27. Ballattori N, Truong AT. Glutathione as a primary osmotic driving force in hepatic bile formation. Am J Physiol 1992; 263: G617-624.

28. Annonymous. Food \& Wine $>$ Health \& Food $>$ Oyster mushroom cuts blood glucose, cholesterol, blood pressure. http://www. whatsonxiamen.com/ wine msg.php?titleid $=564$.

29. Glorioso N, Troffa C, Filigheddu F, Dettori F, Soro A, Parpaglia PP, Collatina S and Pahor M. Effect of the HMG-CoA Reductase inhibitors on blood pressure in patients with essential hypertension and primary hypercholesterolemia. Hypertension 1999; 34:1281-1286.

30. Choudhury BK, Amin SMR, Sarker NC, Khan AS, Mahjabin T, Begum R, Akhtaruzzaman $\mathrm{M}$ and Rahman MS. Impact of Oyster Mushroom (Pleurotus ostreatus) intake on hypertension and blood sugar status of common people of Bangladesh. Bangladesh J Med Biochem 2008; 1: 14-17.

31. Jedinak A and Sliva D. Pleurotus ostreatus inhibits proliferation of human breast and colon cancer cells through p53-dependent as well as p53-independent pathway. Int J Oncology 2008; 33: 1307-1313.

32. Bobek P and Galbavy S. Effect of pleuran (betaglucan from Pleurotus ostreatus) on the antioxidant status of the organism and on dimethylhydrazineinduced precancerous lesions in rat colon. BJ Biomed Sci 2001; 58: 164-168.

33. Zusman I, Reifen R and Livni O. Role of apoptosis, proliferating cell nuclear antigen and p53 protein in chemically induced colon cancer in rats fed corncob fiber treated with the fungus Pleurotus ostreatus. Anticancer Research 1997; 17: 2105-2113.

34. Annonymous. http://www. pleuran.sk/doc/clanky /odborne /BetaGlucan $\% 2$ or\%20 The \% 20 Oyster \% 20 mushroom, \% 20M UDr. Vegh, \% 20MUD Dr. Prochazka, \% 20Lekarni K.pdf.

35. Annonymous. WHY GROW MUSHROOMS, Introduction to Mushroom (Chapter 1). http://www.fungifun.org/mushworld/OysterMushroom-Cultivation/mushroom-growershandbook-1-mushworld-com-chapter-1-1.pdf 